\title{
A CONSTRUÇÃO SOCIAL DO CURRÍCULO DO CURSO DE HISTÓRIA DA UFMG: A PRÁTICA DE ENSINO
}

\author{
Julio Emilio Diniz-Pereira \\ Universidade Federal De Minas \\ Gerais \\ Vyasa Puja Peres Teixeira \\ Universidade Federal De Minas \\ Gerais
}

\section{Resumo}

Este artigo pretende divulgar os resultados de uma pesquisa cujo objeto de análise foi a trajetória do curso de História na Universidade Federal de Minas Gerais (UFMG), na modalidade Licenciatura, com o enfoque na criação e implantação das disciplinas de Prática de Ensino oferecidas pela Faculdade de Filosofia e Ciências Humanas (FAFICH) e as repercussões disso para o Departamento de História da UFMG. Trata-se de uma reflexão acerca do quando, como e porque se deu esse processo de criação e implantação da disciplina de Prática de Ensino, visando contribuir para as discussões, debates e reflexões sobre docentes e futuros docentes do curso de História em relação ao trabalho desenvolvido durante os processos de formação acadêmica.

Palavras-chave: Construção social do currículo; Prática de ensino; Formação de professores de História.

Olh@res, Guarulhos, v. 1, n1, p. 239-262, maio. 2013. 
The social construction of the curriculum in a History teacher education at UFMG: the Practicum

\begin{abstract}
This paper intends to share research findings from an academic study that has analyzed the social construction of the curriculum in a teacher education program in Brazil, in one prestigious research university there: the Universidade Federal de Minas Gerais (UFMG). This program aims at preparing History teachers for teaching both at Middle and High Schools in Brazil. It is clear, through these findings, that reforms in the curriculum depend upon struggles and different strategies developed by different agents involved in this process.
\end{abstract}

Keywords: Social Construction of Curriculum; Practicum; History Teachers' Education. 


\section{Introdução}

Este artigo tem como objetivo divulgar os resultados de uma pesquisa cujo objeto de análise foi a trajetória do curso de História na Universidade Federal de Minas Gerais (UFMG), na modalidade Licenciatura, com o enfoque na criação e implantação das disciplinas de Prática de Ensino oferecidas pela Faculdade de Filosofia e Ciências Humanas (FAFICH) e as repercussões ${ }^{1}$ disso para o Departamento de História da UFMG. Buscamos analisar quando, como e porque se deu esse processo de criação e implantação dessas disciplinas no Departamento. Nosso propósito foi identificar as mudanças ocorridas na configuração curricular e, sobretudo, as ações dos sujeitos envolvidos nessas reformulações. Para tal, considerou-se o contexto específico da Universidade Federal de Minas Gerais, da Faculdade de Filosofia e Ciências Humanas (FAFICH/UFMG), bem como do Departamento de História, assim como o próprio contexto político e educacional do país nas últimas décadas que, sem dúvida alguma, estiveram diretamente relacionados às alterações sofridas pelo curso de História da UFMG.

As pesquisas e as produções acadêmicas realizadas sobre a formação docente em seus vários níveis, inclusive aquelas com foco na formação do professor de História, têm crescido significativamente nos últimos anos. Ilka Miglio de Mesquita e Ernesta Zamboni (2008) apontam que são mais de vinte anos em que a preocupação com a formação do professor de História para a escolarização básica se destaca tanto nos discursos oficiais, como nos discursos acadêmicos. Entretanto, embora haja um crescente aumento de investigações referentes à formação docente, segundo dados de Marli André (2009) e Ernesta Zamboni (2005), nos últimos anos da década de 2000, houve certo abandono da temática sobre a formação inicial. Dessa maneira, uma das intenções de nossa pesquisa foi colaborar para a continuidade

\footnotetext{
1“Repercussões" entendidas aqui como "efeito, influência nos acontecimentos" do Departamento frente à formação de professores.
}

Olh@res, Guarulhos, v. 1, n1, p. 239-262, maio. 2013. 
de trabalhos relacionados à formação inicial, no caso, a formação inicial de professores de História. O nosso interesse é contribuir com o campo de estudos sobre a Licenciatura em História, fornecendo subsídios para uma reflexão mais ampla sobre a formação docente nessa área.

O foco de nossa investigação acadêmica foi, no entanto, a entrada das disciplinas de Prática de Ensino no currículo do curso de História da UFMG. Detivemo-nos, mais detalhadamente, nos momentos de elaboração do currículo, mais especificamente, naqueles nos quais essas disciplinas surgiram, e quais foram os sujeitos envolvidos nesse processo, bem como as posições, intenções e concepções que os mesmos seguiram para conseguirem as mudanças no currículo. Fundamentados na concepção de Ivor Goodson (1995) sobre a construção social do currículo, foi possível observar as relações entre os sujeitos envolvidos nesse processo, percebendo os interesses, conflitos, estratégias, concepções e as lutas que existiram nos momentos de construção social do currículo do curso de História da UFMG.

A abordagem teórico-metodológica adotada no trabalho foi o estudo de caso. Segundo Augusto Triviños (1987), o "estudo de caso é uma categoria de pesquisa cujo objeto é uma unidade que se analisa profundamente. Essa unidade pode ser uma escola, uma universidade, um clube etc.” (TRIVIÑOS, 1987, p. 134). A unidade de análise - ou caso - foi a criação e implantação das disciplinas de Prática de Ensino no Departamento de História da UFMG, buscando compreender as repercussões disso para o próprio Departamento e para o curso.

A coleta de dados foi feita por meio da análise documental, na qual se levantou um considerável número de informações produzidas no Departamento de História da UFMG, contendo dados sobre a instituição, sobre a proposta pedagógica, a organização curricular e como o curso se posicionou frente às mudanças exigidas pela legislação educacional. Foram analisados documentos, tais como o

Olh@res, Guarulhos, v. 1, n1, p. 239-262, maio. 2013. 
histórico do curso, atas de reuniões departamentais, matrizes curriculares, propostas e projetos pedagógicos, composição do corpo docente e dados sobre candidatos ao curso no vestibular. Tudo isso permitiu uma melhor compreensão do cenário institucional no qual o objeto desta pesquisa se situou.

Além da análise documental foram realizadas entrevistas estruturadas com professores do Departamento de História dessa Universidade: responsáveis pela disciplina "Prática de Ensino de História" e excoordenadores do curso. Pretendeu-se, com essas entrevistas, obter informações não encontradas na análise dos documentos. Com os dados reunidos, focamos nossa atenção nas matrizes curriculares que traziam as disciplinas de Prática de Ensino, comparando-as com o currículo que as antecedeu e o que as sucedeu, evidenciando quais as concepções que se destacaram em cada momento de mudança curricular. Os relatos dos entrevistados nos possibilitaram desvelar as motivações e interesses que estiveram por detrás das propostas curriculares em questão.

\section{As mudanças curriculares implantadas em 2001}

As mudanças curriculares no curso de História da UFMG na última década, a de 2001 e, principalmente, a de 2009, diferente das alterações ocorridas nos anos 80, foram mais amplas na modalidade Licenciatura, sobretudo no que se refere às disciplinas de Prática de Ensino. Em sua pesquisa, Cláudia Ricci (2003) também aponta para essa mesma direção. Segundo a autora, a divisão da carga horária de Prática de Ensino parece ter sido a questão central no processo de reformulação curricular.

Em 2001, as disciplinas de Prática de Ensino foram implantadas no curso de História da UFMG para atender a determinação legal estabelecida pela Lei de Diretrizes e Bases da Educação Nacional (LDB) de 1996, ao estipular que os cursos de Licenciatura deveriam ter, no mínimo, 300 horas de "prática de ensino". Naquele momento, a

Olh@res, Guarulhos, v. 1, n1, p. 239-262, maio. 2013. 
legislação não deixava claro o que chamava de "prática de ensino", se essas 300 horas deveriam ser de disciplinas, estágio ou uma combinação dos dois. Ao analisar as diversas entrevistas realizadas para esta pesquisa e também de acordo com o trabalho de Ricci (2003), percebe-se que a formação do professor, até esse momento, não era um tema pautado pelo Departamento de História da UFMG, uma vez que essa formação se resumia, até então, a frequentar as disciplinas pedagógicas oferecidas na Faculdade de Educação (FaE) da mesma Universidade.

As discussões para a implantação das disciplinas de Prática de Ensino no Departamento duraram cerca de cinco anos, de 1996, quando da aprovação da LDB, até 2001, quando foi introduzida a versão curricular com as novas disciplinas. Segundo entrevista de um professor do Departamento, durante as primeiras discussões, sugeriuse que parcela das 300 horas fosse absorvida pelo Departamento de História ${ }^{2}$.

A partir das entrevistas realizadas para esta pesquisa, observou-se que a "opção" do Departamento de História da UFMG em ficar com parte da carga horária de "prática de ensino" foi fruto de intensos debates e disputas entre os profissionais da Instituição. Como indica Goodson (1995), o currículo é uma arena onde convivem vários tipos de interesses e relações de dominação. Desse modo, era de se esperar que surgissem conflitos durante as discussões e definições sobre a reforma do curso de História dessa Universidade. As falas desses professores revelam a existência de tensões entre a necessária adequação curricular frente às exigências legais da LDB e a apropriação das 180 horas de "prática de ensino" a cargo do Departamento de História. Cabe aqui destacar que o grupo de professores que compunha o Departamento não era homogêneo, havendo diferenças e divergências de opinião em relação à formação do professor de História.

\footnotetext{
${ }^{2}$ Dessas 300 horas de "prática de ensino", o Departamento de História ficou com 180 horas, divididas em três disciplinas: as Práticas de Ensino de História I, II e III. As 120 horas restantes ficaram com a Faculdade de Educação, para serem desenvolvidas na forma de estágio supervisionado.
}

Olh@res, Guarulhos, v. 1, n1, p. 239-262, maio. 2013. 
Por meio das entrevistas foi possível perceber a existência dentro do Departamento de História da UFMG de dois grupos de professores: um mais preocupado com a pós-graduação, a pesquisa e a formação de bacharéis e outro preocupado não só com essas questões, mas também com a formação de professores. Tal divisão foi melhor evidenciada quando se observou as posições que os docentes assumiram nas discussões sobre as reformas curriculares do curso de História da UFMG.

As posições assumidas por um dos professores entrevistados na pesquisa sobre a reforma curricular de 2001 o colocam no grupo de docentes que estavam mais preocupados com a pós-graduação, a pesquisa e a formação de bacharéis. O ponto central de suas preocupações era que o novo currículo espelhasse as linhas de pesquisa do Departamento e da pós-graduação. Segundo ele, a partir dessa reforma, o foco do curso, por causa do crescimento da pósgraduação, não seria mais a formação de professores:

\begin{abstract}
Me parece que o lado da prática de ensino, de formação de professores... perdeu com isso. Quer dizer, na realidade, era uma proposta que tinha sido feita lá nos anos 80 , quando um grupo achava que não deveria ter pós-graduação e ser realmente só formação de professores. E um outro grupo dizia: "Não! Nós temos que ter pesquisa! Qual é o papel de um Departamento de História na UFMG?" Então, esse grupo, de certa forma, acabou sendo hegemônico. (Professor B, entrevista realizada com professor do Departamento de História da UFMG, em 22/11/2010).
\end{abstract}

Apesar de esse professor considerar que o grupo da pesquisa e da pósgraduação tenha sido "hegemônico", o grupo de professores preocupados também com a formação docente se fez representar, pois parte da carga horária de "prática de ensino" ficou no Departamento. Ainda segundo esse professor, apesar do Departamento ter aceitado parte da carga horária de "prática", por meio da implantação das disciplinas de Prática de Ensino no curso de História, as discussões de caráter mais didático, relacionadas à educação básica, aconteceram muito pouco no Departamento:

Olh@res, Guarulhos, v. 1, n1, p. 239-262, maio. 2013. 
Existem alguns professores que até têm sim uma preocupação com isso... mas todos eles são professores muito produtivos em termos da pós-graduação e não necessariamente apenas com essa área [refere-se à Educação] e como também nós temos excelentes professores que têm essa preocupação na Faculdade de Educação, eu acho que fica um pouco... Por mais que tenha boa vontade de alguns professores aqui etc e tal. Eu acho que ainda é... talvez não seja um projeto tão... da participação mais efetiva da formação, além da formação dos conteúdos de história propriamente. Essa reflexão de caráter mais didático, institucional e político do ensino, seja da escola pública, seja da escola particular, quer dizer, esse tipo de reflexão eu acho que é pouco feita aqui. E eu imagino que seja muito feita na FaE. Então, eu pessoalmente fico pensando assim: para mim, o ideal seria existir um trabalho mais articulado com a FaE, mais, vamos dizer assim, de um processo em que talvez essa formação de professores ficasse sob inteira responsabilidade da $\mathrm{FaE}$, ainda que alguns professores daqui quisessem participar de algum modo mais efetivo nessa transição do aluno, num acompanhamento. [...] Tanto melhor serão esses professores quanto melhor forem os conteúdos de História que nós, no momento que eles estão aqui, estudarem com a gente. No momento que eles estão na $\mathrm{FaE}$, eles vão discutir todas essas questões de política educacionais, de didática e essas coisas todas. (Professor C, entrevista realizada com professor do Departamento de História da UFMG, em 29/11/2010).

Para esse professor, toda a questão didático-pedagógica em relação à formação de professores, bem como debates e discussões à respeito da escola básica deveriam ficar a cargo apenas da Faculdade de Educação (FaE). É possível inferir que o Departamento, mesmo tendo concordado em criar disciplinas de Prática de Ensino, mas não tendo nenhuma linha de pesquisa na Pós-graduação sobre o "ensino de História", acabe não contribuindo de maneira mais contundente para as discussões sobre o ensino e consequentemente para a formação de professores. Entretanto, em vez de propor a criação de uma linha de pesquisa sobre o "ensino de História" e, a partir disso, pensar em maneiras de buscar uma articulação maior entre graduação e pósgraduação, bem como entre disciplinas de conteúdo e disciplinas pedagógicas, esse professor prefere deixar toda essa responsabilidade a cargo da Faculdade de Educação:

Se perguntar pra mim eu diria: "Tudo a cargo da FaE!" Eu sou uma pessoa muito tradicional. Eu acho que a gente compra pão é na padaria e peixe é na peixaria. Eu acho bacana essas pessoas muito inovadoras, que misturam tudo, mas, às vezes, eu acho que isso tem que ser um projeto completo. Então, alguns professores aqui têm pesquisa... por isso eles gostariam que fosse aqui. Eles até tem... Então, é saber em qual grau, qual comprometimento, qual grupo, qual organicidade, que linha de pesquisa? Então, não sei se é o caso. (Entrevista realizada com professor do Departamento de História da UFMG, em 22/11/2010).

Olh@res, Guarulhos, v. 1, n1, p. 239-262, maio. 2013. 
Todo esse discurso representa o pensamento de uma parcela dos professores do Departamento de História e demonstra que apesar das pesquisas sobre formação de professores e da legislação educacional apontarem para a importância de se romper com a chamada "fórmula $3+1$ " e com a interpretação equivocada de que a licenciatura é responsabilidade apenas das faculdades e departamentos de Educação, essa perspectiva ainda existe. Com isso, a nossa pesquisa mostrou que a discussão sobre "a quem cabe ministrar a disciplina Prática de Ensino" ainda não está superada. É justamente o contrário. Esta continua sendo um ponto de tensão, conflito e de relação de poder no interior do campo universitário. Segundo Souza (2007), apesar de não ser o principal problema da formação docente, a "fórmula 3+1" produziu historicamente uma cisão entre os conteúdos do ensino e os processos de ensino-aprendizagem. Disso deriva um entendimento equivocado de que cabe aos institutos o ensino dos conteúdos e à Faculdade de Educação o da docência, o que retiraria daqueles a responsabilidade pela formação de professores e limitaria esta à instrumentalização para o trabalho. (SOUZA, 2007, p. 38.) (Ver também DINIZ-PEREIRA, 2000). Anna Maria Carvalho e Denice Catani (1988) apontam na mesma direção ao colocarem que os institutos de conteúdos específicos e as faculdades de educação não assumem a corresponsabilidade nas estruturas curriculares dos cursos de licenciatura.

Apesar de parcela dos professores do Departamento entender que a FaE deveria ficar com toda a responsabilidade sobre a formação docente, decidiu-se, por meio de uma série de discussões ${ }^{3}$, que o Departamento ficaria com 180 horas da carga horária de "prática de ensino" e que estas seriam trabalhadas na forma de três disciplinas de 60 horas cada. Em um primeiro momento, imaginou-se que essas disciplinas funcionariam no recém-criado Laboratório de Ensino da FAFICH/UFMG, assumindo o mesmo nome desse espaço: "Laborató-

\footnotetext{
${ }^{3}$ De acordo com as atas de reuniões disponíveis para consulta no Colegiado do curso de História da UFMG, a média de participantes das reuniões era de nove pessoas, contando com o coordenador do Colegiado, a secretária, discentes e docentes.
}

Olh@res, Guarulhos, v. 1, n1, p. 239-262, maio. 2013. 
rio de Ensino I, II e III". Posteriormente, elas ganharam o nome atual de "Prática de Ensino de História, I, II e III".

A decisão sobre a criação das disciplinas de Prática de Ensino na FAFICH foi fruto de disputas entre os professores do curso, tanto os do Departamento de História como os da FaE. Como afirma Goodson (1995), na medida em que as mudanças no currículo são um processo que envolve escolhas e interesses, as lutas são quase inevitáveis. Pois, como nos lembra Tomaz Tadeu da Silva (1995, p. 08), as mudanças curriculares são processos constituídos de "conflitos e lutas entre diferentes tradições e diferentes concepções sociais."

Dessa maneira, a defesa da criação das disciplinas de Prática de Ensino no Departamento de História se deu por meio de um discurso sobre a "preocupação" de alguns professores sobre a ênfase do trabalho na FaE: "as questões dos métodos, do transmitir, esquecendo-se do conteúdo". As falas abaixo reforçam esse discurso ao demonstrarem tal "preocupação":

De um lado, eu fico preocupada com um certo discurso, um certo discurso... não estou dizendo que na Pedagogia haja uma homogeneidade nesse sentido, mas eu acho que uma parte do discurso que vem da Pedagogia, da Faculdade de Educação... isso não é só aqui na UFMG, acho que em outras universidades do Brasil também... é um discurso que ressalta muito as técnicas, propriamente a questão didática e uma certa crítica, que as vezes eu acho exagerada e ou infundada, na ênfase no conteúdo, então, critica-se o "conteudismo". [...] A minha preocupação, eu acho que você estando fazendo Mestrado lá na Faculdade de Educação, talvez tenha uma visão bem mais clara do que eu sobre isso... mas a minha impressão é que há uma parcela dos pedagogos que, de fato, não dão a importância devida à formação na área do conhecimento, do conhecimento que se dá aula, privilegiando muito a parte didática, pedagógica, das técnicas do ensino e menos na formação da área. Eu acho que não se pode priorizar uma coisa ou outra. (Entrevista realizada com professora do Departamento de História da UFMG, em 15/12/2010).

Eu acho que professores da Faculdade de Educação, ao darem a psicologia, ao darem a sociologia, eles se esquecem um pouco do que eles estão fazendo, quem é aquele público que esses professores estão lidando. Eu estou fazendo generalização apressada. Eu tenho colegas que eu tenho profunda admiração tanto aqui quanto na Faculdade de Educação e que são excelentes profissionais, que os meus alunos fazem os maiores elogios. Mas eu acho que falta essa... essa aproximação prática, sabe? Talvez, eu... A gente até tentou... com a psicologia, por exemplo... a psicologia não discute coisas que são básicas para o professor de História como as noções de tempo, espaço... E, fica se perdendo em coisas que... o bebê ...E não resolve, não resolve o problema que é aquilo com que... o problema que o aluno vai encontrar... o professor, o licenciando vai encontrar. (Professor A, entrevista realizada com professor do Departamento de História da UFMG, em 12/11/2010).

Olh@res, Guarulhos, v. 1, n1, p. 239-262, maio. 2013. 
Desse modo, alguns professores usaram o argumento de que as disciplinas na FaE estavam muito desconectadas das discussões mais específicas sobre a formação de professores de História para reivindicar as "Práticas de Ensino" para o Departamento de História da UFMG. As "falas" dos professores entrevistados parecem demonstrar certa falta de conhecimento do que realmente ocorre na Faculdade de Educação, evidenciando ainda uma visão estereotipada em relação ao trabalho realizado na FaE.

Além da "preocupação" de alguns professores com o trabalho realizado na $\mathrm{FaE}$, algumas entrevistas evidenciaram que se vivia um momento bastante favorável para a criação das disciplinas de Prática de Ensino no Departamento de História da UFMG, pois a diretoria da FAFICH também se mostrava interessada nas questões relacionadas ao "ensino":

Por tudo isso, nós pedimos, nós reivindicamos... $\mathrm{Na}$ época, havia um momento favorável... a diretoria estava acompanhando... até se criou uma sala com o nome de "Laboratório" e tal.[...] Eu fui um dos que defendeu a ideia de que a disciplina de Prática de Ensino... O Departamento deveria ter disciplinas de Prática de Ensino. Elas não deveriam ficar todas na FaE... (Professor D, entrevista realizada com professor do Departamento de História da UFMG, em 29/11/2010).

Foi feita uma proposta na FAFICH da criação de um laboratório de Prática de Ensino. [...] Então, essa ideia de criar um espaço próprio, um laboratório... porque achavam que essa era uma prática muito importante e que de alguma forma a FAFICH deveria participar dessa formação de professores também. Para não ser uma coisa assim: "Só lá na FaE... Ah não! Porque aqui é conteúdo, bacharelado e na FaE... a discussão é na FaE. [...] Então, essa foi a experiência... muito dentro desse contexto... mas ainda um pouco com alguns professores que sentiam que havia uma importância, que o Departamento deveria valorizar a formação de professores. Deveria discutir junto com a FaE essa... deveria dividir essa responsabilidade da formação de professores. (Professor B, entrevista realizada com professor do Departamento de História da UFMG, em 22/11/2010).

É importante destacar que apesar do momento ter sido considerado favorável por alguns professores, houve resistências no interior do próprio Departamento de História que refletiam o desejo de alguns professores para que o Departamento não assumisse parte da carga

Olh@res, Guarulhos, v. 1, n1, p. 239-262, maio. 2013. 
horária de "prática de ensino", entendendo que a FaE deveria ficar com toda a responsabilidade sobre a formação pedagógica dos professores de História. Perceber as dimensões conflituosas na elaboração do currículo é algo de grande relevância, como já destacavam Goodson (1995) e Apple (1979). Deste modo e de acordo com as ideias desses autores, ao conhecermos as lutas existentes na criação e implantação das disciplinas de Prática de Ensino no currículo do curso de História da UFMG, isto nos auxilia a não naturalizar concepções e formas curriculares, que antes de tudo, são resultados de processos histórico-sociais.

Os conflitos em torno da criação e implantação dessas disciplinas também revelam a existência de relações de poder no interior no Departamento de História da UFMG. Essa questão nos remete a algo que Forquin (1993) aponta em sua obra quando se refere aos momentos de construção do currículo, nos quais a seleção de conteúdos é realizada por pessoas que "falam" de um "lugar específico", situado em uma hierarquia social em que uns tem mais poder que outros. Dessa maneira, em meio a essas lutas, o discurso que prevaleceu foi o da implantação das disciplinas de Práticas de Ensino no curso de História.

Na versão curricular de 2001, as disciplinas de Prática de Ensino foram alocadas no $4^{\circ}, 5^{\circ}$ e $6^{\circ}$ períodos. A proposta curricular do curso de História da UFMG, em 2001, apresentou ementas bastante parecidas para essas disciplinas, mudando apenas o recorte temporal. Por meio dessas ementas, não foi possível ter muita clareza sobre o que era efetivamente trabalhado nas "Práticas de Ensino", nem perceber uma conexão entre as três disciplinas. Também não ficou claro qual a natureza dessas disciplinas, se seriam teóricas, teóricopráticas ou somente práticas. Segundo entendimento de um professor do Departamento, elas teriam: "uma carga horária teórica zero e uma carga horária prática de quatro créditos”. Por meio das entrevistas e

Olh@res, Guarulhos, v. 1, n1, p. 239-262, maio. 2013. 
dos programas de curso disponibilizados pelo Colegiado ${ }^{4}$, percebeu-se que essas disciplinas não tiveram os objetivos claramente declarados, ou seja, os professores que ministravam essas disciplinas poderiam trabalhar da maneira que achassem mais adequada:

...simplesmente nós pegamos uma carga horária para dar
prática e você dá o que quiser desde que seja prática!
Pode ser desde: "Vamos fazer atividades e
disponibilizar para os alunos da rede e que eles venham
aqui assistir". Ou não: "Vamos dar aulas para nós
mesmos". (Professor C, entrevista realizada com
professor do Departamento de História da UFMG, em
29/11/2010). Os programas de curso apresentavam uma grande diversidade de temas abordados, como: "história e cinema", "análise do livro didático", "periodização da historiografia do livro didático", "metodologia da investigação ao ensino de história", "produção de material didático", discussões sobre a escola atual, o currículo, as estratégias e a avaliação, "o que é ser professor de história hoje”, “a História nos séculos XIX, XX e XXI", outras linguagens como revistas, jornais, Internet, música, "História do ensino de História", entre outros.

A bibliografia proposta para fazer tais discussões é tão vasta quanto os temas. Entretanto, paradoxalmente, é possível destacar a pequena presença de textos relativos ao ensino e ao ensino de História, principalmente nos programas das disciplinas de Prática I e II. Algumas referências bibliográficas são citadas por todos os programas de curso: "História e Ensino de História" de Thaís Nívea de Lima e "Inaugurando a História e construindo a nação" de Lana Mara Castro e Thaís Nívea de Lima. Os demais textos sobre o "ensino" variam de programa para programa.

A criação dessas disciplinas no Departamento deixou a desejar, pois elas não conseguiram atingir seus objetivos iniciais, segundo depoimento dos próprios professores. Algumas razões apontadas para

\footnotetext{
${ }^{4}$ No total foram reunidos dez programas de curso, sendo: cinco de Prática de Ensino I, de dois professores diferentes; dois de Prática de Ensino II, dos mesmos professores da Prática I e três de Prática de Ensino III, com um mesmo professor, único concursado para essa disciplina. Os programas são dos anos de 2002, 2003, 2004, 2005, 2006, 2007 e 2010. Tanto o Colegiado do curso quanto o Departamento não têm todos os programas dessas disciplinas. Todos os professores que ofertaram essas disciplinas foram contatados, mas somente alguns disponibilizaram os programas.
}

Olh@res, Guarulhos, v. 1, n1, p. 239-262, maio. 2013. 
o não cumprimento dos propósitos iniciais dessas disciplinas foram: a falta de professores com um perfil específico para elas; o descompasso entre as linhas de pesquisa da pós-graduação e as discussões nas disciplinas de Prática de Ensino; a falta de diálogo entre as disciplinas de conteúdo e as "Práticas de Ensino" e, até mesmo, "uma certa desvalorização por parcela dos professores do Departamento em relação à formação de professores".

Para tentar solucionar a questão da falta de professores com um perfil específico para ministrar as disciplinas de Prática de Ensino, realizouse um concurso, em 2002, para "Prática de Ensino e História do Brasil". Depois desse concurso, não houve mais nenhum outro com essa mesma ênfase no Departamento de História da UFMG. O único professor concursado para a Prática de Ensino assumiu de maneira mais efetiva somente a disciplina de Prática de Ensino III. As demais foram assumidas por professores "emprestados", que demonstravam uma maior sensibilidade, um maior interesse na área de ensino ou, simplesmente, porque não havia mais ninguém para ministrá-las:

Os demais [professores de Prática de Ensino] vêm emprestados, fazem uma espécie de favor. Então, fica assim: sempre a prática é aquele "patinho feio" que ninguém pega ou que pega aquele que não tem muito prestígio para pegar outra. (Professor A, entrevista realizada com professor do Departamento de História da UFMG, em 12/11/2010).

O problema que eu acho que nós temos até hoje... temos apenas um professor que tem uma dedicação maior e um interesse em ensino e pesquisa nessa área do ensino de História, particularmente de Prática de Ensino de História e de experiência de ensino de História no ensino fundamental, médio e superior [...]. E aí, as disciplinas de Prática de Ensino nem sempre eram ministradas por professores que tinham interesse mais claro nessa área. [...] Então, de fato, eu acho que ainda que tenhamos alguns outros professores no Departamento com interesses na área de ensino, [...] que chegaram a dar Prática de Ensino e tal, mas eu acho que para esses outros professores, este não é o foco principal do interesse. [...] Nem sempre encontravam professores realmente dispostos a dar a disciplina Prática de Ensino no Departamento. Alguns professores ofertavam, aceitavam ofertar, mas não era a primeira opção. (Professor D, entrevista realizada com professora do Departamento de História da UFMG, em 15/12/2010).

De uma forma ou de outra, têm alguns professores que estão se aproximando e ministrando sistematicamente esse ensino de Prática. Uns com desempenho melhor, outros com desempenho pior; uns com mais paixão, outros com menos paixão; uns como obrigação, outros não. (Professor $\mathrm{C}$, entrevista realizada com professor do Departamento de História da UFMG, em 29/11/2010)

Olh@res, Guarulhos, v. 1, n1, p. 239-262, maio. 2013. 
Sobre o impacto ${ }^{5}$ da criação das disciplinas de Prática de Ensino no

Departamento de História da UFMG, apesar de alguns entrevistados

dizerem que "houve ganho" com tal criação, pois o Departamento

passou a pensar sobre a formação de professores, há sentimentos

muito distintos em relação a esse ponto. Entre os entrevistados que

consideraram que a criação das disciplinas de Prática de Ensino trouxe

benefícios para o Departamento, alguns são mais otimistas quanto a

esse "ganho", outros nem tanto, pois acreditam que esse "ganho" não

foi o bastante para provocar mudanças mais profundas:

Eu acho que houve uma série de dificuldades, mas assim, de um modo geral, a reforma de 2001, eu acho que foi mais positiva que negativa. Eu acho que tivemos mais ganhos do que perdas. Ganhos porque a formação do professor, apesar das dificuldades, ela passou a ser... tem um pouco mais de importância no curso. Ela começou a ser repensada. [...] Com a entrada das três "Práticas", eu já falei anteriormente, eu acho que foi um ganho no sentido de fazer o Departamento pensar nisso. Então, levou o Departamento a pensar nessa questão da licenciatura, da prática de ensino. Eu acho que a entrada do professor [concursado para Prática de Ensino], que procurou casar muito bem tanto o interesse de ensino e pesquisa na área de ensino de História como o de Brasil Colonial, História do Livro e da Leitura, História das Edições... enfim, os campos de pesquisa que ele tem interesse. Ele sempre procurou fazer com que essas áreas fossem convergentes. Então, eu acho que foi um ganho para os alunos e, além disso, alguns outros professores do Departamento, mesmo que ainda que não tivessem pesquisa na área de ensino de História, mas que tinham um certo interesse nessa área, acabaram concordando em assumir disciplinas de Prática de Ensino. Eu acho que alguns foram mais bem sucedidos no ensino dessas disciplinas, outros nem tanto. Alguns ficaram mais tempo à frente dessas disciplinas, outros tiveram uma experiência efêmera. Mas eu acho que o ganho foi este: levar os professores a colocarem a questão da licenciatura como uma questão do Departamento. (Professor D, entrevista realizada com professora do Departamento de História da UFMG, em 15/12/2010).

Eu acho que não trouxe um impacto muito grande não. Sinceramente eu acho que não. Eu acho que a graduação aproveita muito mais o desenvolvimento da pós[graduação]. Nós temos alguns pesquisadores que são realmente de ponta. Tem uma inserção nacional, internacional, sabe? E eu acho que isso, comparativamente falando, fala muito mais alto do que

\footnotetext{
5 "Impacto" entendido aqui como "efeito, influência nos acontecimentos" no Departamento frente à formação de professores.
}

Olh@res, Guarulhos, v. 1, n1, p. 239-262, maio. 2013. 
essas questões aí. (Professor B, entrevista realizada com professor do Departamento de História da UFMG, em 22/11/2010).

Eu acho que o impacto deixou a desejar. Eu gostaria que essa questão aparecesse de forma mais... aparecesse de forma melhor, com maior intensidade, com mais veemência nas nossas disciplinas, na prática nossa de sala de aula. Mas elas não têm aparecido. Não que eu consiga detectar. [...] Mas assim, continua, embora várias pessoas tenham preocupação, tenham interesse, continua sendo uma coisa muito desconectada da nossa prática. Até mesmo eu que estou falando. Porque a coisa está longe. Não está... Nós não temos aqui um ou dois professores ligados à Prática que ficam discutindo a questão da Educação de História. Agora mesmo está rolando um evento ali no Sônia Viegas, que alguns alunos do curso de História, em articulação com um professor da FaE, trouxeram uma escola para fazer. Por que eles quiseram trazer escola pra cá e não para a FaE? Porque eles querem colocar os meninos aqui para que o pessoal lembre que tem educação na jogada. Então, é uma perspectiva ainda muito ausente. (Professor C, entrevista realizada com professor do Departamento de História da UFMG, em 29/11/2010).

Então, os benefícios foram muito pequenos. Eu sou muito crítico em relação aos benefícios. Eu acho que houve algum benefício. Uma colega [da $\mathrm{FaE}$ ], quando estava na Prática de Ensino, me disse que melhorou... a qualidade dos alunos que chegavam lá... a qualidade dos alunos que chegavam na $\mathrm{FaE}$ melhorou a partir dessa introdução, mas que tudo dependia muito do professor, de quem tinha sido professor desse aluno aqui. Então, um benefício pequeno e estreito. [...] O impacto para o Departamento foi, por um lado, chamar uma ou outra pessoa para atuar na área e, na maioria, um alheamento total já em relação à questão da Prática de Ensino e um preconceito também muito grande. Preconceito grande! Eu acho que ainda é uma coisa que não merece muito elogio, nem aprovação. Eu acho que, por exemplo, teve uma coisa que foi até positiva. Eu fiz um projeto... dois projetos de construção de material didático... até são materiais que estão no site... E isso, como ganhou dinheiro, bolsa para o Departamento, isso um pouco mudou a imagem dos professores. Mas assim, pouco. Continua sendo assim: trabalho dele, não trabalho nosso. [...] Ficou a parte. Ainda que eu tenha colegas que tenham dado algum retorno, mas ficou assim um trabalho muito, muito a parte. (Professor A, entrevista realizada com professor do Departamento de História da UFMG, em 12/11/2010).

A maioria das pesquisas sobre formação docente aponta que em muitas universidades brasileiras, como o caso da UFMG, nas unidades de conteúdos específicos, como é o caso da FAFICH, existem dentro do mesmo curso a modalidade Licenciatura e Bacharelado, aparecendo uma duplicidade em seus objetivos: formar professores e pesquisadores. Muitos autores acusam um certo descaso com a Licenciatura por sua vinculação com a formação do professor, refletindo, dessa maneira, o desprezo com que as questões relacionadas ao ensino são tratadas nas universidades (DINIZPEREIRA, 2006).

Em suma, é possível constatar que a criação das disciplinas de Prática

de Ensino no Departamento de História da UFMG foi, aparentemente,

Olh@res, Guarulhos, v. 1, n1, p. 239-262, maio. 2013. 
resultado de uma "simples" adequação à legislação educacional, mas, indubitavelmente, aconteceu por meio de lutas e do estabelecimento de estratégias de parcela dos professores do Departamento para este ficar com uma parte da carga horária de "prática de ensino". A criação de tais disciplinas no Departamento de História da UFMG parece ter sido um passo importante. No entanto, há ainda muito que fazer em relação ao compromisso com a questão da formação de professores de História nesse Departamento.

\section{As mudanças curriculares implantadas em 2009}

Em 2002, segundo ano de implantação das disciplinas de Prática de Ensino no Departamento de História da UFMG, o Conselho Nacional de Educação (CNE) aprovou uma Resolução ${ }^{6}$, estabelecendo que as licenciaturas devessem ter, no mínimo, 400 horas de "prática como componente curricular" e, no mínimo, 400 horas de estágio supervisionado. O Departamento começou, então, novos debates sobre essa nova exigência de adequação curricular, em fins de 2004 e início de 2005, sendo o novo currículo implantado somente a partir do segundo semestre de 2009.

A nova reformulação curricular, de acordo com um professor entrevistado para esta pesquisa, "se deu na marra", "Não foi um projeto proposto; foi um projeto imposto!” A nova mudança não foi fruto de uma vontade interna, de uma maior preocupação com a Licenciatura, mas apenas para uma adequação às novas exigências legais colocadas pelo governo federal. Os professores entrevistados criticaram esse novo projeto por considerarem excessivo o número de horas de "prática" e de estágio. Segundo eles, seria muito difícil incorporar essa carga horária à estrutura curricular existente, o que acabaria resultando em um curso de História com uma duração de

\footnotetext{
${ }^{6}$ O Parecer CNE/CP 28/2001 e a Resolução CNE/CP 2/2002 tratam especificamente da duração da carga horária dos cursos de licenciatura.

Olh@res, Guarulhos, v. 1, n1, p. 239-262, maio. 2013.
} 
quatro anos e meio ou cinco anos. Isto, na opinião deles, não seria viável.

O aumento que foi proposto... que foi imposto! ...é um aumento sem condições. As instituições não têm estrutura para dar conta disso. É um aumento que sacrifica em demasia os docentes e, sobretudo, os estudantes. Eu acho que ele é pouco razoável. [...] Essa proposta de aumento da carga horária de estágio e de prática foi uma proposta irrealista. Eu chego a dizer, quase irresponsável. Que não levou em consideração as condições reais das universidades de se organizarem para incorporá-las e nem das escolas de educação básica para receberem esses alunos. [...] Isso, então, criou uma dificuldade enorme para se incorporar essa carga horária à estrutura curricular existente. Há uma carga horária prevista para o curso de História e a gente lida com uma questão muito séria. A gente sabe muito bem que as instituições particulares de ensino criam mecanismos para driblar essa legislação. E a gente cumpre. Cumprindo a legislação, corria-se o risco de construir um curso de História que duraria quatro anos e meio... cinco anos. (Professor A, entrevista realizada com professor do Departamento de História da UFMG, em 12/11/2010).

Eu, particularmente, acho que 800 horas é um exagero! Porque eu não acredito que o aumento no número de horas, de fato, tenha necessariamente uma melhora qualitativa na formação desses professores. Eu acho que antes... na reforma que foi implementada em 2001, de fato, era muito pouco mesmo... Além das disciplinas da Faculdade de Educação, eram 120 horas de prática e estágio casadas, que, de fato, poderia ser considerado pouco. [...] De fato, é muito pouco porque o tempo que o aluno passava na escola era uma vivência muito rápida. Então, eu acho que o aumento, na época, para 300 horas de prática, com visitas a escola e tudo... eu acho que, de fato, naquela época, foi um aumento de se repensar as licenciaturas... Agora o aumento de 300 horas para 800 , eu realmente acho bastante questionável. Porque obrigou os cursos de licenciatura a diminuir muito a carga horária de conhecimento específico. E nós decidimos não aumentar o curso além dos 4 anos, porque é um tempo que julgamos excessivo para o aluno ficar dentro da universidade. Até naquela concepção de que a formação é continuada, você pode ter quatro anos ou cinco anos, mas o bom profissional, na verdade, tem que aprender a aprender; na sua formação, ele tem que saber isso. Como buscar conhecimento de forma autônoma e como buscar esse conhecimento depois da graduação, por meio de novos cursos, seja de uma especialização ou pós lato-sensu ou cursos de extensão ou aperfeiçoamento. E, nesse sentido, quer dizer, você aumentar para cinco anos era uma decisão discutível, principalmente, no curso noturno... E então, decidimos manter o curso com quatro anos! Mas, para isso, tivemos que diminuir a carga horária de optativas e eletivas, de formação complementar, mais particularmente, de optativas, o que eu acho que não é necessariamente um ganho, eu acho que é uma perda! Eu sinceramente questiono muito essa decisão do MEC de aumentar para 800 horas... eu acho que 300 horas de prática ou de estágio bem pensadas e aperfeiçoadas em relação ao que era até 2008 ... eu acho que tinha que aperfeiçoar ou, talvez, aumentar para, no máximo, 400 horas ao todo, entre prática de ensino e estágio. Talvez fosse uma decisão mais realista e mais produtiva. (Professor D, entrevista realizada com professor do Departamento de História da UFMG, em 15/12/2010).

O projeto de mudança curricular do curso de História da UFMG, de 2009, teve duas versões. Na primeira versão, conforme um professor do Departamento, participante da elaboração do novo projeto, procurou-se seguir à risca as determinações do Conselho Nacional de

Olh@res, Guarulhos, v. 1, n1, p. 239-262, maio. 2013. 
Educação, sob a orientação da Pró-Reitora de Graduação da Universidade: Por meio de um depoimento bastante revelador de como as questões sobre "ensino" são ainda tratadas no interior do Departamento de História da UFMG, esse mesmo professor afirmou que essa primeira versão de reforma curricular foi amplamente "combatida" dentro do Departamento por mudar o perfil do curso, fazendo com que ele "se tornasse um curso com cara de formação de professores"; pela falta de recursos, tanto materiais quanto humanos, para fazer tais mudanças; pela falta de experiência e tradição em relação à formação docente; por mexer com os preconceitos dos próprios professores do Departamento que não viam o ensino como algo de grande importância:

\begin{abstract}
Então, foi feita uma primeira versão. Essa primeira versão foi apresentada aqui no Departamento de História e foi uma versão enormemente combatida. Por quê? Porque ela mudava radicalmente o perfil do curso de História, na medida em que dava a esse curso a cara de formação de professores. Segundo, era um pouco aventureira na medida em que a gente não tinha material, recurso humano para fazer isso... a gente não tinha uma história, uma tradição... e mexia também com os preconceitos dos próprios professores do Departamento que vêem o ensino, a educação como algo de menor importância, menos distinção. A academia é uma instituição ainda do Antigo Regime. E aí, então, eles não viam com ânimo qualquer investimento que fosse... bons olhos, que fosse por aí. Então, o projeto foi sabotado! Eu quase apanhei quando apresentei o projeto. (Professor A, entrevista realizada com professor do Departamento de História da UFMG, em 12/11/2010).
\end{abstract}

Conforme esse mesmo professor, com a mudança na coordenação da Pró-Reitoria de Graduação da UFMG, houve a possibilidade de uma "outra interpretação" sobre as exigências legais da Resolução 02/2002. Os elaboradores da nova versão curricular procuraram abarcar as "800 horas exigidas" da seguinte maneira: criaram-se duas novas disciplinas chamadas de "Prática de História", no segundo e terceiro períodos, com 60 horas cada. Essas disciplinas tinham como objetivo contemplar todas as atividades que envolvessem uma dimensão prática para que fossem computadas como carga horária "prática" do curso. Ou seja, elas contabilizam as horas gastas pelos

Olh@res, Guarulhos, v. 1, n1, p. 239-262, maio. 2013. 
alunos fazendo trabalhos "práticos", não somente nas disciplinas de Prática de Ensino, mas em todas as disciplinas do curso. A criação dessa nova disciplina gerou algumas críticas dentro do Departamento. Chegou a ser chamada de "disciplina fantasma", o que, segundo esse professor, "é um equívoco", pois os alunos do curso de História "têm uma grande carga de leitura e pesquisa fora da sala de aula e isso precisaria ser computado". Essa "outra interpretação" sobre as exigências legais, não seguindo a risca o que a legislação exigia, pode ser considerada uma maneira de "burlar" as indicações da legislação, apesar do depoimento desse professor tentar indicar o contrário.

Uma segunda mudança na estrutura curricular diz respeito às disciplinas de Prática de Ensino que sofreram uma remodelação, alterando o nome e passando a se chamar "Análise da Prática de História/Estágio de História I, II, III ${ }^{7}$ ". Houve, com isso, um aumento de sua carga horária para 120 horas nas duas primeiras disciplinas ${ }^{8}$ e 135 horas na terceira ${ }^{9}$.

Nas ementas dessas disciplinas, diferentemente da versão curricular de 2001, percebe-se uma mudança considerável em relação às atividades e habilidades que se pretende desenvolver ao longo das três disciplinas, ou seja, percebe-se uma maior clareza quanto aos objetivos das disciplinas e a possibilidade de uma maior articulação entre elas. Alguns professores entrevistados também apontam para a existência de uma maior articulação não só entre essas três disciplinas,

\footnotetext{
${ }^{7}$ Essas disciplinas continuaram a ser realizadas no Departamento de História. Outras duas disciplinas de mesmo nome: "Análise da Prática de História/Estágio de História IV e V" passaram a acontecer na Faculdade de Educação.

${ }^{8}$ Análise da Prática Pedagógica/Estágio de História I: 120 horas das quais 30 horas são de orientação presencial e 90 horas de atividades de estágio compreendidas da seguinte forma: 30 horas no campo de estágio e 60 horas para elaboração de relatórios e planejamento de atividades; Análise da Prática Pedagógica/Estágio de História II: 120 horas das quais 45 horas são de orientação presencial e as demais 75 horas de atividades de estágio a serem distribuídas: 30 horas no campo de estágio e 15 horas para planejamento e elaboração de relatórios.

9 Análise da Prática Pedagógica/Estágio de História III: 135 horas das quais 45 horas destinadas à orientação presencial e 90 horas reservadas às atividades de estágio, sendo estas últimas assim distribuídas: 30 horas no campo de estágio e 60 horas reservadas para elaboração de relatórios e planejamentos.
}

Olh@res, Guarulhos, v. 1, n1, p. 239-262, maio. 2013. 
mas também entre elas e disciplinas similares ministradas na Faculdade de Educação:

Essa três novas.... elaboradas na versão curricular de 2009 [...] as três disciplinas têm ementas... então, elas não são livres; têm prática... os objetivos são claramente declarados, as atividades são muito bem definidas. [...] Estas são três disciplinas profundamente articuladas. (Professor C, entrevista realizada com professor do Departamento de História da UFMG, em 29/11/2010).

Se você observou, tem um contínuo... tem uma gradação, um crescimento... para que chegue na $\mathrm{FaE}$ um aluno, na sala de aula, regendo turma... nas Práticas de Ensino da FaE. (Professor A, entrevista realizada com professor do Departamento de História da UFMG, em $12 / 11 / 2010)$.

O projeto pedagógico de 2009 procurou, ao menos intencionalmente, promover um diálogo maior entre as disciplinas pedagógicas de conteúdo específico ${ }^{10}$ do curso de História da UFMG, buscando incrementar a qualidade da formação docente oferecida. Entretanto, como o projeto foi implantado somente a partir do segundo semestre de 2009 e as disciplinas de Análise da Prática de História/Estágio de História começaram a acontecer apenas a partir do primeiro semestre de 2011, não foi possível, durante a pesquisa, fazer um diagnóstico sobre a efetivação desse projeto, pois se tratava de uma mudança em curso.

\section{Considerações Finais}

Por meio desta pesquisa, percebeu-se que todo esse movimento para as reformulações curriculares no curso de História da UFMG - na última década, a de 2001 e a de 2009 -, foi resultado de grandes disputas e conflitos dentro do Departamento. Na medida em que a elaboração de um novo currículo envolve escolhas e interesses, os embates são praticamente inevitáveis, como nos indica Goodson (1995). Ainda conforme esse autor, como qualquer outra construção social, as modificações no currículo ocorrem em uma arena, no caso, o Departamento de História da UFMG, em que vários interesses, confli-

\footnotetext{
${ }^{10} \mathrm{O}$ termo "disciplina pedagógica do conteúdo" foi utilizado por Shulman (1987) para se referir às disciplinas, também conhecidas como "integradoras", que fazem análises sobre a transposição do conhecimento científico da área para o ensino fundamental e médio.
}

Olh@res, Guarulhos, v. 1, n1, p. 239-262, maio. 2013. 
tos, relações de poder e de dominação acontecem. Forquin (1993) aponta na mesma direção ao indicar que o currículo é um "produto social" que ocorre no interior de uma "arena social" enquanto resultado de interações e interpretações "negociadas" entre sujeitos colocados em posições sociais diferentes e, por isso, portadores de “perspectivas" divergentes (p. 83).

Nas reformas aqui estudadas, alguns grupos portadores de interesses e de ideologias específicas tiveram mais poder de imposição e de controle simbólico do que outros. As discussões sobre a criação das disciplinas de Prática de Ensino no Departamento de História não foram neutras, nem fortuitas. Elas implicaram em distintos interesses dos docentes do Departamento que incorporavam perspectivas diferentes e divergentes em relação à formação docente.

Perceber todos esses conflitos contribui para o entendimento que toda mudança curricular é complexa e envolve diferenças e divergências. Apesar da sociedade tender ao consenso e negar a necessidade do conflito em virtude de um equilíbrio social e da preservação do sistema, é necessário que os conflitos sejam encarados como uma dimensão básica e, em geral, dialética da sociedade (APPLE, 1979). Elucidar o contexto histórico, social, político e econômico em que se desenvolvem as mudanças curriculares, destacando a posição dos indivíduos envolvidos nos processos de elaboração desses currículos, bem como suas articulações, interesses, conflitos e lutas, favorecem tanto a visão das questões microssociológicas envolvidas nos processos de elaboração dos currículos quanto na análise macrossociológica dos mesmos.

Como todo ponto de chegada significa um outro ponto de partida, as questões aqui desenvolvidas podem ter outras significações. Nesta pesquisa, estiveram presentes opções, expressões, interpretações e escolhas teóricas. Contudo, esperamos que o que foi apresentado contribua para reflexões acerca das disciplinas de Prática de Ensino de História. Colaborando ainda com outras discussões mais específicas sobre a formação do professor de História.

Olh@res, Guarulhos, v. 1, n1, p. 239-262, maio. 2013. 


\section{Referências Bibliográficas}

ANDRÉ, M. (org). A produção acadêmica sobre formação de professores: um estudo comparativo das dissertações e teses defendidas nos anos 1990 e 2000. Revista Formação Docente, v.01, n.01, p.41-56, ago-dez. 2009. Disponível em: $<$ http://formacaodocente.autenticaeditora.com.br/artigo/exibir/1/7/1>. Acesso em: 01 jan. 2011.

APPLE, Michael W. Ideologia e currículo. São Paulo: Brasiliense, 1982.

BRASIL. Ministério da Educação. Lei no 9.39420 de dezembro de 1996. Estabelece as Diretrizes e Bases da Educação Nacional, DF, 20 de dezembro de 1996. Disponível em < http://portal.mec.gov.br/sesu/arquivos/pdf/lei9394.pdf>

Parecer CNE/CP 09/2001 de 8 de maio de 2001. Diretrizes Curriculares Nacionais para a Formação de Professores da Educação Básica, em nível superior, curso de licenciatura, de graduação plena. Brasília: MEC/CNE, 2001. Disponível em: <http://portal.mec.gov.br/cne/arquivos/pdf/009.pdf>.

. Parecer CNE/CES 28/2001 de 2 de outubro de 2001. Dá nova redação aos Parecer CNE/CP 21/2001, que estabelece a duração e a carga horária dos cursos de Formação de Professores da Educação Básica, em nível superior, curso de licenciatura, de graduação plena. Brasília: MEC/CNE, 2001. Disponível em: <http://www.uems.br/proe/sec/Parecer\%20CNE-CP\%20028-2001.pdf>.

Resolução CNE/CP n ${ }^{\circ}$ 1, de 18 de fevereiro de 2002. Institui

Diretrizes Curriculares Nacionais para a Formação de Professores da Educação Básica, em nível superior de licenciatura, de graduação plena. Brasília: MEC/CNE, 2002. Disponível em: < http://portal.mec.gov.br/cne/arquivos/pdf/rcp01_02.pdf>.

Resolução CNE/CP n 2 2, de 19 de fevereiro de 2002. Institui a duração e a carga horária dos cursos de licenciatura, de graduação plena, de formação de professores da Educação Básica em nível superior. Brasília: MEC/CNE, 2002ª . Disponível em: $<$ http://portal.mec.gov.br/cne/arquivos/pdf/CP022002.pdf $>$.

CARVAlHO, Anna Maria Pessoa de. e VIANNA, Deise Miranda. A quem cabe a licenciatura. Ciência e Cultura, São Paulo, 40 (2): 143-47, 1988.

DINIZ-PEREIRA, Júlio Emílio. Relações de Poder no interior do campo universitário e as licenciaturas. Caderno de Pesquisa nº 11, Dezembro / 2000.

Olh@res, Guarulhos, v. 1, n1, p. 239-262, maio. 2013. 
Formação de professores: pesquisas, representações e poder. $2^{\mathrm{a}}$ Edição. Belo Horizonte: Autêntica, 2006.

FORQUIN, Jean-Claude. Escola e Cultura: as bases sócias e epistemológicas do conhecimento escolar. Tradução de Guacira Lopes Louro - Porto Alegrre: Artes Médicas, 1993.

As abordagens sociológicas do Currículo: orientações teóricas e perspectivas de pesquisa. Educação e Realidade, vol.21, nº 1, 1996.

GOODSON, Ivor F. Currículo: teoria e história. Tradução Atílio Brunneta. 6 $6^{\mathrm{a}}$ d. Petrópolis, RJ: Vozes 1995.

Políticas de currículo e de escolarização. Ed. Petrópolis, RJ: Vozes, 2008.

MESQUITA, Ilka Miglio de; ZAMBONI, Ernesta. A Formação de Professores na Trajetória Histórica da Associação Nacional de História (ANPUH). In: ZAMBONI, Ernesta; FONSECA, Selva Guimarães (orgs.). Espaços de formação do professor de história. Campinas, SP: Papitus, 2008.

RICCI, Cláudia Regina Fonseca Miguel Sapag; SILVA, Marcos Antonio da. A formação do professor e o ensino de história. Espaços e dimensões de práticas educativas. 2003. Tese (doutorado) - Universidade de São Paulo.

SILVA, Tomaz Tadeu. Prefácio. In: GOODSON, Ivor F. Currículo: teoria e história. Tradução Atílio Brunneta. 6a Ed. Petrópolis, RJ: Vozes 1995.

SOUZA, João Valdir. (org). Formação de professores para a Educação Básica: Dez anos de LDB. Belo Horizonte: Autêntica, 2007.

TRIVIÑOS, Augusto Nibaldo Silva. Introdução à pesquisa em ciências sociais: a pesquisa qualitativa em educação. São Paulo: Atlas, 1987.

UNIVERSIDADE FEDERAL DE MINAS GERAIS. Proposta Curricular História 2001, Belo Horizonte, 46 p.

. Projeto Pedagógico 2009, Belo Horizonte, 35 p.

ZAMBONI, Ernesta. Encontros Nacionais de Pesquisadores de História - perspectivas. In: NETO, José Miguel Arias (org). Dez anos de Pesquisas em Ensino de História. Londrina: AtrioArt, 2005.

Olh@res, Guarulhos, v. 1, n1, p. 239-262, maio. 2013. 